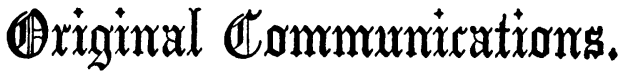

\section{BINOCULAR OPHTHALMOSCOPY.}

By J. Zachariah Laurence, F.R.C.S., M.B., Surgeon to the Surrey Ophthalmic Hospital.

THE problem of binocular ophthalmoscopy appears, at first sight, sufficiently simple, and so I thought it myself. I regarded the aërial image of the fundus oculi, which is formed in front of the object-glass, as any other ordinary visible object, from every component luminous point of which rays of light diverged in all possible directions. The problem appeared then solved by having a larger mirror than usual, pierced with two eye-holes at a distance equal to that of the pupils of the eyes. I had such a mirror actually constructed; and went so far as to publish an account of it in the Medical Times and Gazette; but soon had reason to regret this publication, by finding my instrunent was really not a binocular one. The fact is, that the aërial image of the fundus oculi differs from an ordinary object, in having the course of the rays of each of its component luminous points predetermined by the converging action of the object-glass. This will become plain from an inspection of the annexed figure.

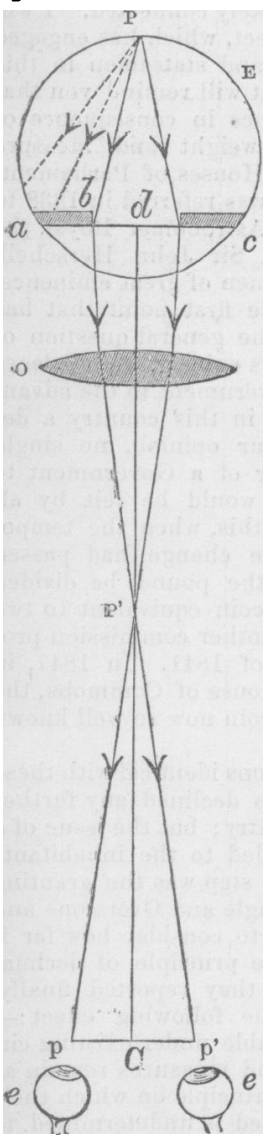

Fig. 1.
Let the eye under observation be $\mathrm{E}$ (Fig. 1), e, e, the eyes of the observer, $P$ any luminous point of the fundus oculi. The rays diverging from $P$ will be, for the greater part, stopped from passing out of the eye $E$, by a diaphragm - the iris, $a, b, c$-and the other opaque tunics of the eye (the dotted rays from $P$ re. present some rays thus stopped). The extreme possible size, then, of the conical pencil of rays from $\mathbf{P}$, is a cone, whose base equals the area of the pupil, the diameter of which we will assume at its maximum degree of dilata. tion, to be, say, five-sixteenths of an inch. The rays of this pencil striking the object-glass o (which may be one of two inches and a half focus, and held, say, half an inch from the cornea of $E$ ), are reunited by it to a focus at $\mathbf{p}^{\prime}$ -at the focal length of 0 -(in myopic eyes somewhat nearer, in hypermetropic ones somewhat further off.) From $P^{\prime}$ the rays of the convergent pencil again diverge. It is hence clear our eyes can, under the most favourable circumstances, only simul. taneously receive those two parts of the two halves of the pencil which happen to have such a degree of divergence as just to strike our two pupils. Let us suppose that our two eyes, re. spectively, will obtain enough of the pencil for distinct vision of $P^{\prime}$, if each eye only receive one single extreme ray, $P^{\prime} p$ and $P^{\prime} p^{\prime}$, of each outermost side of the pencil. At what distance from P' must we place ourselves (taking our pupils as two inches and a half apart) for this purpose? Approximatively, we may answer this question by the proportion (Euclid vi, 4 ),

$$
P^{\prime} \mathrm{c}: \mathrm{P}^{\prime} d: \text { : p'c : } b d \text {. }
$$

Substituting the numerical values of $P^{\prime} d, p^{\prime} c$, and $b d$ we find that $P^{\prime} C=24$ inches $=$ the distance we shall have to retreat from $P$ ' for its binocular perception-too great a distance for all practical purposes, more especially with the excessively feeble illumination, that would attend the exclusion of all but the extreme rays of each pencil.

With my formerly proposed instrument, the fundus oculi may be seen binocularly; but one has to retreat to so far a distance from the observed eye, as to render the image faint and unsatisfactory in the last degree.* My friend, Dr. Giraud.Teulon of Paris, has devised an ophthalmoscope (Fig. 2) which obviates this objection. Using the same figure again (which for simplicity's sake

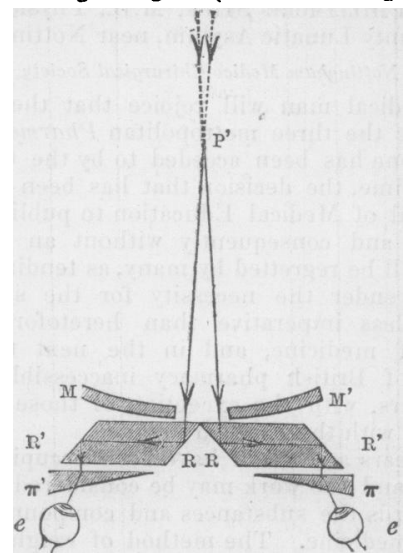

Fig. 2.-Giraud-Teulon's instrument.

we only delineate from $P^{\prime}$ on). Behind the ophthalmoscope mirror $\mathrm{M} \mathrm{M}^{\prime}$ is placed a pair of rhombs of glass. Any ray, as $P$ 'R, striking a rhomb at $R$, is reflected in the direction $R R^{\prime}$; from $R$ ' it is again reflected straight down to the eye at $e$. The effect of this is that we see two images of 'P', one with either eye; these double images are then made to coalesce by a pair of Brewster's prisms $\left(\pi, \pi^{\prime}\right)$, and thus binocular (stereoscopic?) vision is obtained of the point $P$ '.

I have recently simplified this instrument by substituting for the rhombs ordinary reflectors of quicksilvered glass or speculum.metal (Fig. 3). The simple proper

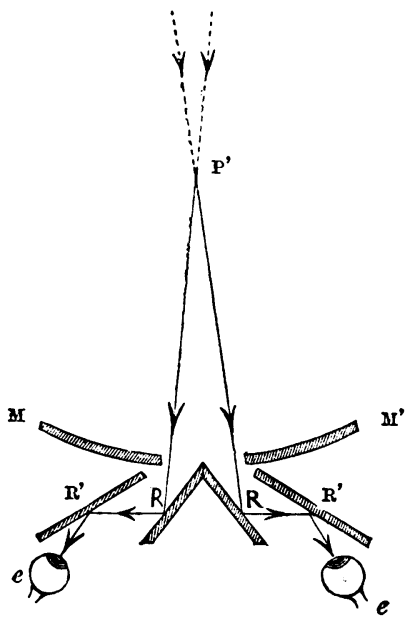

Fig. 3.-Author's instrument.

* These objections do not apply to the use of my ophthalmoscope mirror for a laryngoscope. 
inclination of the reflectors $R^{\prime} R^{\prime}$ suffices (on the principle of Wheatstone's reflecting stereoscope) to effect the coalescence of the double images without any additional prisms.* This form of instrument admits of adjustment of the eye-mirrors ( $\left.R^{\prime} R^{\prime}\right)$ to suit both the different separ. ation of the eyes met with in different individuals, as also any deviations of accommodation.

\section{THE BRITISH PHARMACOPEIA, WITH REFERENCE TO WEIGHTS} AND MEASURES.

By W. Philimone Stiff, M.B., Physician to the County Lunatic Asylum, near Nottingham.

[Real at the Nottingham Medico-Chirurgical Society, Oct.10th, 1862.] Everx medical man will rejoice that the proposal to consolidate the three metropolitan Pharmacopoias into a British one has been acceded to by the Colleges. At the same time, the decision that has been arrived at by the Council of Medical Education to publish it in Eng. lish only, and consequently without an official Latin version, will be regretted by many, as tending in the first place to render the necessity for the study of that language less imperative than heretofore upon the student of medicine, and in the next to make the standard of British pharmacy inaccessible to foreign philosophers, with the exception of those few who are acquainted with the English tongue.

Three years and a half have been occupied in its preparation; and the work may be considered complete, as far as regards the substances and compounds to be employed in medicine. The method of weighing remedies -the first and most important proceeding in pharmacyis, however, left undetermined, and the publication deferred to an indefinite period. The difficult question of weights and measures has created a complete deadlock, and brought the labours of the Committee to a stand-still. Legislative interference is called for, if not to settle, at least to compromise, the vexed question.

The readers of the British Medical Journar, have been put in possession of the Report of the Pharmaco. pocia Committee of the Medical Council, at p. 582 of the last volume ; and two very instructive leaders have been published as commentaries upon that document. It will be seen that the authors of the new Pharmacopoia, like some of their predecessors, propose an alteration of the weights in rommon use, nothing less than a new unit, differing from the imperial one, and made by dividing the avoirdupois ounce into $\mathbf{4} 80$ parts, instead of $43 \pi \frac{1}{2}$. This would have the effect of introducing into daily practice two different kinds of grains, one being abont one-eleventh less than the other; two distinct scruples; and as many as three drachms-viz., the avoirdupois of 27.3 grains, the apothecaries' of 60 grains, and the new drachm of 54.6 grains.

Briefly expressed, the alteration is this ; that whereas the present imperial grain accumulates into ounces and pounds of different values, the converse now takes place, and the ounce diminishes into two sorts of grains. The change becomes still more important from the fact that, as medicines are taken in the smaller quantities, every new prescription will be affected by it; whilst at present the inconvenience of having two sorts of pounds, one of 7000 grains and the other of 5760 , is practically unimportant to the physician, who seldom brings them juto comparison.

The subject of weights, measures, and coinage is deserving of much more attention than it has yet received from the profession; and the unsatisfactory condition of the former gave rise to the efforts of the Committee to

* This instrument was manufacturer by Messrs. Murray and Heath, of 43 , Piceadilly. remedy it. It is apparent to every one that there is no necessity for weighing drugs by a standard distinct from the imperial; nor strietly equitable that the apothecary shall buy at 16 ounces, anả sell at 12 ounces, to. the pound.

At first sight, the apparently simple and feasible planc of abandoning apothecaries' weight, and adopting avoir dupois in its entirety, presents itself. This is verye popular with some writers. T'wo great objections meet us-the awkward fractional division of the ounce; and the ever recurring confusion that would arise between $\bar{\Phi}$ the present drachm of 60 grains to be abandoned, and one of 27.34375 grains to be established. It has been pro-es posed to use the grain only, and divide the ounce decimally; but we cannot abolish the imperial drachm. This scheme would result in the use of the old drachm for old prescriptions, the imperial drachm by the public and decimal divisions by the prescriber.

The Committee, by recommending a different courses altogether-viz., the adoption of a unit of new value and by referring to the legislature for powers-have raised two very important questions, which assumes larger proportions under discussion:-1. What system of metrology ought we to adopt? 2. By what scalec shall we calculate our weights and measures? I therefore propose to give a brief summary of the more salient? points bearing on these subjects, with which also thequestion of the coinage is intimately connected. I will not detail the history of the subject, which has engagedo the attention of mathematicians and statesmen in this country for nearly a century; but will remind you that 3 it assumed considerable importance in consequence of the loss of the standards of weight and measure in the fire which destroyed the Houses of Parliament. $\vec{\infty}$ The problem of their restoration was referred in 1838 too a commission consisting of the Astronomer Royal, $e^{N}$ President of the Royal Society, Sir John Herschell, Peacock, Dean of Ely, and other men of great eminene. In 1841 they reported, "that the first point that called for our special notice is the general question ?of decimal scale. In introducing this subject, we beg leave to invite the attention of the Government to the advan. tage and facility of establishing in this country a decimal system of coinage. In our opinion, no single $\overrightarrow{\vec{\sigma}}$ change which it is in the power of a Government to 3 effect in our monetary system would be felt by all classes as equally beneficial with this, when the tempo rary inconvenience attending the change had passed. away." They recommend that the pound be divided into a thousand parts, and a new coin equivalent to two shillings irtroduced. In $\mathbf{1} 8 \pm 3$, another commission proposed to carry out the report of 1841 . In 1847, in accordance with a vote of the House of Commons, the tenth of a pound was struck, the coin now so well known as the graceless florin.

Notwithstanding recommendations identical with these propositions, the Government has declined any furthero extension of this plan in this country; but the issue of a tenth of a penny has been conceded to the inhabitantso of Malta and others. The next step was the granting of letters patent to Lords Monteagle and Overstone and을 Mr. Hubbard, instructing them to consider how far it was practicable to introduce the principle of decimal division into the coinage; and they reported finally, NN Lord Monteagle excepted, to the following effect:"That it does not appear desirable under existing cir cumstances, while our weights and measures remain aso at present, and so long as the principle on which their simplification ought to be founded is undetermined, toc disturb the established habits of the people with regard to the coins now in use by a partial attempt to introduce any new principle into the coinage alone."

Considerable obloquy has been cast upon the re-(ָ) porters for their alleged one-sidedness, as it was gene- $\frac{?}{\Phi}$ rally understood that they were unfavourable to the 